\title{
Development of safe construction temperature ranges to avoid blow-ups in Ultra-Thin Concrete Pavements
}

\author{
Johannes Mentz ${ }^{*}$, and Anton Hartman ${ }^{2}$ \\ ${ }^{1}$ Aurecon, Pavement and Materials Department, Aurecon Centre Tshwane Pretoria, South Africa \\ ${ }^{2}$ Aurecon, Pavement and Materials Department, Aurecon Centre Tshwane Pretoria, South Africa
}

\begin{abstract}
After the construction of an ultra-thin concrete pavement, ambient temperatures may induce an axial force within the pavement due to thermal expansion that can lead to the formation of a blow-up failure. By analysing the mechanism of a blow-up, temperature differentiates at which a blow-up failure in ultra-thin concrete pavements may occur were identified. Safe construction temperature range graphs were produced for different ultra-thin concrete pavements to serve as a guideline that would potentially limit the occurrence of blow-ups.
\end{abstract}

\section{Introduction}

The South African road network is an ageing part of the country's infrastructure. With $70 \%$ of the network exceeding the 20 year design life, innovative repair and construction methods were required to rectify this problem [1].

Ultra-Thin Continuously Reinforced Concrete Pavements (UTCRCP) were developed as one such solution. The most significant difference between UTCRCP and conventional Continuously Reinforced Concrete Pavements (CRCP) is the thickness of the pavement structure. While CRCP typically varies between $150 \mathrm{~mm}$ up to $300 \mathrm{~mm}$, UTCRCP is typically $50 \mathrm{~mm}$ thick. In addition, UTCRCP utilizes concrete with a very high strength (exceeding $80 \mathrm{MPa}$ compressive strength) and a high percentage of steel (usually $50 \times 50 \times 5.6 \mathrm{~mm}$ steel mesh), while it also contains a large volume of steel fibres and also polypropylene fibres [2].

During the early development of UTCRCP, the potential of using thin concrete in low volume roads was identified and this lead to the development of Ultra-Thin Reinforced Concrete Pavements (UTRCP). UTCRP differs from UTCRCP in that a lower volume of steel (typically $100 \times 100 \times 4 \mathrm{~mm}$ steel mesh) and lower strength concrete (typically $30 \mathrm{MPa}$ compressive strength) is used [3].

The failure modes of ultra-thin concrete pavements were interrogated during initial heavy vehicle simulator testing [1]. Unfortunately the trial strips were generally short, did not always incorporate anchor end stops and failure modes were mainly load associated cracking and potholing. These conditions did not favour thermal expansion related failures and accordingly it did not receive significant research attention. The focus of this investigation is blow-ups, also referred to as pop-ups, as typically shown in Figure 1, in UTRCP. There is general consensus that blow-ups are caused by axial compressive forces within the pavement structure. The axial forces are induced into the pavement through a rise in temperature or moisture changes [4].

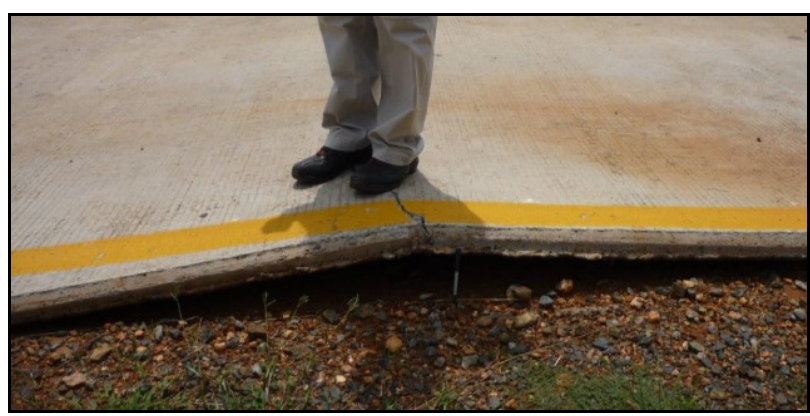

Figure 1 : Typical example of a buckling blow-up failure in an ultra-thin concrete pavement

The blow-ups are typically accompanied with transverse cracks or joints in the pavements. The thermal expansion of the pavement is critical to activate this mechanism. Thermal expansion is dependent not only on temperature of the pavement, but also the moisture within the pavement. The increase or decrease of the moisture within the pavement may be represented by an equivalent increase or decrease of temperature [5]. This is due to the thermal expansion coefficient increasing or decreasing with a corresponding increase or decrease in moisture [6].

The use of safe temperature construction limits is well known in the road construction industry, with authorities restricting the construction of bituminous seals to warmer periods of the year. The calculation of safe construction temperature ranges to prevent thermal buckling failure is primarily used in rail construction [7].

* Corresponding author: Johannes.Mentz@aurecongroup.com 
It is of crucial importance for Continuously Welded Rails (CWR) to ensure that excessive tension and compression forces are not present in the rail to avoid either rail breaks or kick-outs. This investigation attempts to establish such temperature ranges for the construction of UTRCP pavements.

\section{Background Theory}

The development of safe temperature construction range graphs for ultra-thin concrete pavements, UTRCP, may reduce the occurrence of blow-ups within the pavement. If a pavement is constructed and adheres to the temperature limits prescribed, it should ensure that no excessive strain is developed in cold weather or excessive axial forces are induced by warm weather.

The blow-ups of CRCP pavements have been extensively researched [8]-[17]. The analysis of the phenomenon focuses on the axial force induced into the concrete pavement by a rise or fall in temperature and/or moisture. Research conducted by Kerr [4], [5], [18] identified three modes (cases) of buckling of a concrete pavement as indicated in Figure 2:

- continuous pavement with no joint, also referred to as unhinged;

- continuous pavement with a joint or crack, hinged;

- continuous pavement adjoining a rigid structure, typically at an anchor beam.

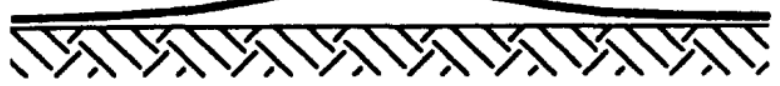

(a) Case (I)

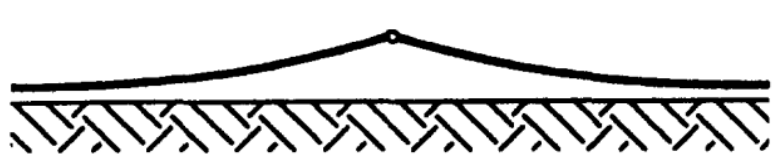

(b) Case (II)

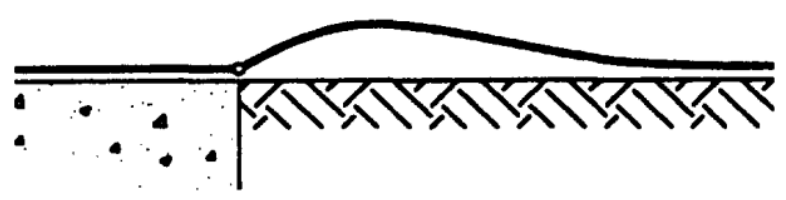

(c) Case (III)

Figure 2 : The three modes investigated by Kerr (Kerr, 1997)

Kerr confirmed that the most critical case is where a joint or a large spalling crack is located in a continuous pavement (Case II). As continuously reinforced concrete pavements are designed without joints but with regular narrow (less than $0.5 \mathrm{~mm}$ in width) transverse cracks, a load case somewhere between an unhinged (Case I) and hinged (Case II) is applicable for the current study.

The use of conventional beam-buckling theorem, to determine the force at which the concrete pavement will buckle, is considered as erroneous. This is because beam-buckling does not account for the resistance to buckling provided by the self-weight of the pavement that influences the solutions significantly [18].
The analysis of Kerr represented the concrete pavement as a rectangular beam on a rigid base as indicated in Figure 3. The axial force induced by a temperature increase is represented by $\mathrm{Nt}$, the reduced axial force after a blow-up is represented by $\tilde{N} t$ in the lift-off region of 21 . In the adjoining regions, the axial force, $\mathrm{N}$, varies due to the shearing resistance to axial displacements. The joint in the centre of the illustration is also the point $\mathrm{x}$, where the largest lift-off may be expected after a blow-up.
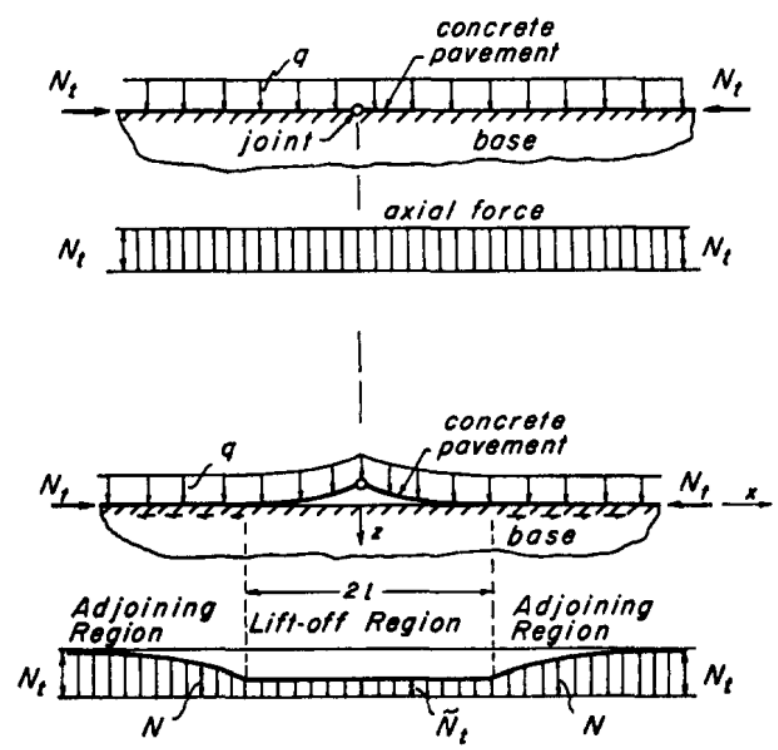

Figure 3 : Axial forces in a concrete pavement after a blow-up [18]

The temperature at which a blow-up could occur was determined by further analysis of this model. The maximum temperature without a blow-up occurring was presented by $\Delta \mathrm{T}_{\mathrm{L}}$. The temperature increase in the pavement was represented by $\Delta \mathrm{T}_{0}$. Thus, for a range 0 $<\Delta \mathrm{T}_{0}<\Delta \mathrm{T}_{\mathrm{L}}$, no blow-up in the concrete pavement is expected, but any instance at which $\Delta \mathrm{T}_{0}>\Delta \mathrm{T}_{\mathrm{L}}$, a blow-up is possible.

For ultra-thin concrete pavements, the formulas used to represent the mode of failure for a concrete pavement without a joint/crack were the following [18]:

$$
\lambda l=4.4934
$$

$\alpha \Delta T_{0}-\tilde{N}_{t} / E A=\sqrt{ }\left(\left(2 r_{0}\right) / \mu E A \ln \left(\cosh \left\{\mu\left(\alpha \Delta T_{0}-\tilde{N}_{t} / E A\right) l-J\right\}\right)\right)$

Where

$$
\begin{aligned}
& J=0.001023 q^{* 2} l^{7} \\
& \lambda=\sqrt{ }\left(\left(\tilde{N}_{t}\left(1-v^{2}\right)\right) / E I\right) \\
& q^{*}=\left(q_{0}\left(1-v^{2}\right)\right) / E I
\end{aligned}
$$


With

$\alpha=$ coefficient of linear thermal expansion for the concrete $\left(\alpha=9 \times 10^{-6} /{ }^{\circ} \mathrm{C}\right)$

$\mathrm{E}=$ Young's modulus for the concrete (GPa), refer to Table 1

$\mathrm{A}=$ cross sectional area of the pavement $(\mathrm{b} \times \mathrm{h}$; with $b$ the width of the pavement and $h$ the height of the pavement, typically $50 \mathrm{~mm}$ for UTRCP)

$\mathrm{r} 0=$ sliding frictional resistance at the interface of the pavement and the base per unit length and width of pavement

$\mu=$ curve fitting parameter for the sliding frictional resistance to test data $(\mu=1000 / \mathrm{m})$

$\tilde{\mathrm{N}} \mathrm{t}=$ axial force in the pavement

$\mathrm{q}^{*}=$ unit weight of the pavement per meter length

$\gamma=$ unit weight of the pavement material $(\gamma=$ $\left.23.6 \mathrm{kN} / \mathrm{m}^{3}\right)$

$1=$ half the length of the lift-off region of the pavement since the uplift is symmetric

The Young's Modulus of the concrete differs for UTRCP, as it is not the same for all the design codes. For the analysis the values given by Euro code [19] was used. Alkali-silica reactions have not been included in the study as it is assumed that care will be taken to avoid such aggregates when constructing ultra-thin concrete pavements.

Table 1: Concrete Modulus of Elasticity

\begin{tabular}{|c|c|c|c|c|}
\hline \multirow{2}{*}{$\begin{array}{c}\text { Cube } \\
\text { Strength } \\
\text { (MPa) }\end{array}$} & \multicolumn{4}{|c|}{ Young's Modulus (GPa) } \\
\cline { 2 - 5 } & Euro & SANS & BS & \\
& {$[19]$} & $\begin{array}{c}10100 \\
{[20]}\end{array}$ & $\begin{array}{c}8110- \\
1: 1997\end{array}$ & $\begin{array}{c}\text { ACI 318M- } \\
05 \text { [22] }\end{array}$ \\
\hline 25 & 30 & 26 & 21 & 21 \\
\hline 30 & 31 & 28 & 23 & 23 \\
\hline 35 & 32 & 29.5 & 24 & 25 \\
\hline
\end{tabular}

The expected vertical displacement of the pavement can be calculated by using equation (6). For the maximum deflection of the pavement, $\mathrm{x}$ is equal to zero since the maximum deflection occurs in the middle of the lift-off region.

$w_{l}(\mathbf{x})=\left(q^{*} / 2 \lambda^{4}\right)\left[2 \lambda l(\cos \lambda \mathbf{x}-\cos \lambda l) / \sin \lambda l+(\lambda \mathbf{x})^{2}-(\lambda l)^{2}\right]$

With the above equations, a positive value is assumed for the axial force within the pavement. With the now known axial force, lambda $(\lambda)$ can be calculated along with 1 (length), the term $\mathrm{J}$ and a solution can be found for $\Delta \mathrm{T}_{0}$ through equation (2). From the solution of the equations over a multitude of axial forces, graphs can be developed for a concrete pavement without a joint.

The formulas used to represent the mode of failure for a concrete pavement with a joint/crack were the following, with equation (2), (4) and (5) unchanged:

$$
\begin{aligned}
& \lambda l=2.3311 \\
& J=0.0063 q^{* 2} l^{7}
\end{aligned}
$$$$
w_{l}(\mathbf{x})=\left(q^{*} / 2 \lambda^{4}\right)[\cos \lambda \mathbf{x}+[(\sin \lambda l-\lambda l) / \cos \lambda l] \sin \lambda \mathbf{x}
$$$$
\left.-1+(\lambda \mathbf{x})^{2} / 2-(\lambda l)^{2} / 2\right]
$$

For each of the modes of failures, a minimum temperature increase to cause lift-off, i.e. a blow-up, can be determined for different thicknesses.

\section{Determination of Blow-up Failure Temperatures}

The relationship between temperature and vertical displacement has a parabolic shape representing the post-buckling equilibrium displacements as indicated in Figure 4 and Figure 5, where $\mathrm{h}$ denotes the thickness of the concrete. The equilibrium branch to the left of the minimum value represents the unstable mode of failure that may occur described as a shattering blow-up.

The equilibrium branch to the right represents the stable failure mode or a buckling blow-up. Shattering type blow-ups are more likely to occur in UTRCP pavements due to the lower compressive strength concrete used, with buckling blow-ups more common in UTCRCP pavements. Figure 6 and Figure 7 indicate the relationship between the axial force and vertical displacement and confirm high axial compressive forces with minimal up lift for shattering blow-ups.

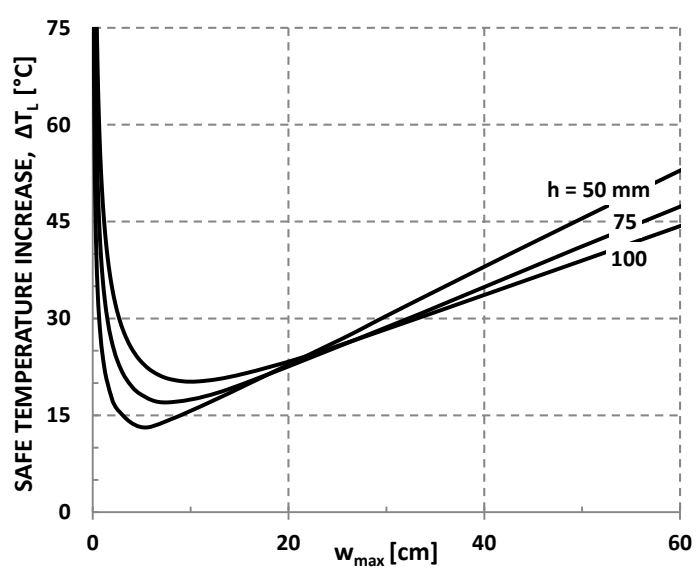

Figure 4: Equilibrium branches for UTRCP with a joint/crack 


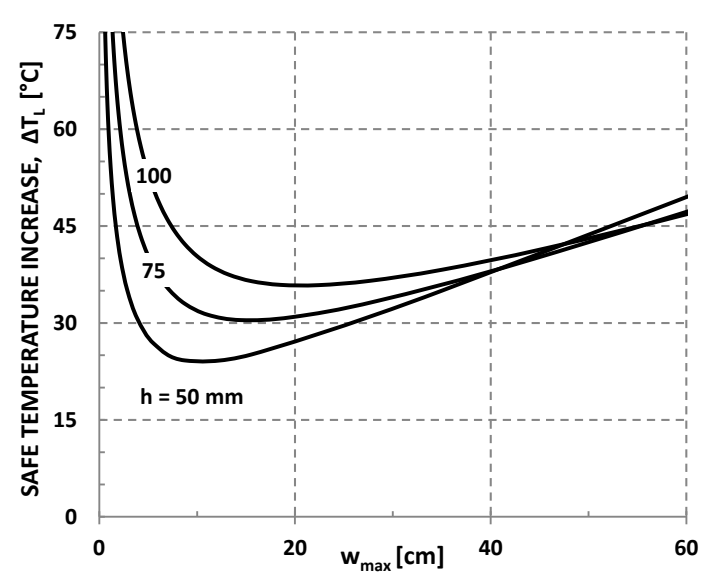

Figure 5: Equilibrium branches for UTRCP without a joint/crack

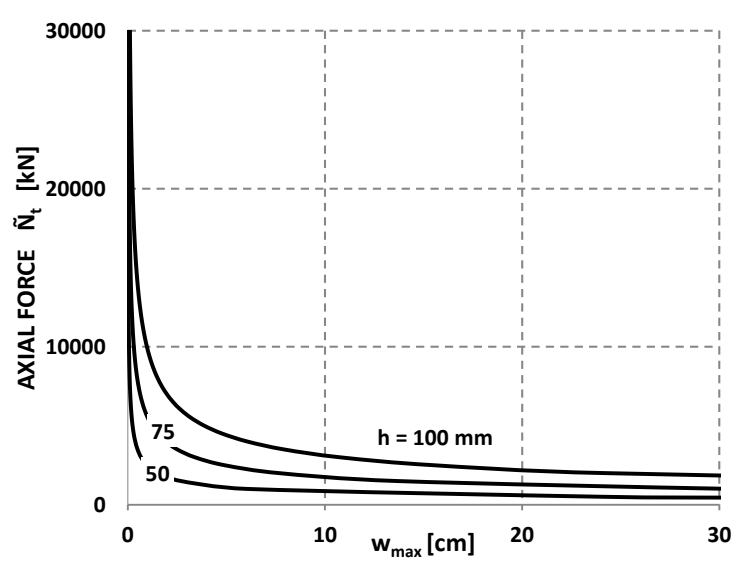

Figure 6: Axial forces, Ñt, for UTRCP without a joint/crack

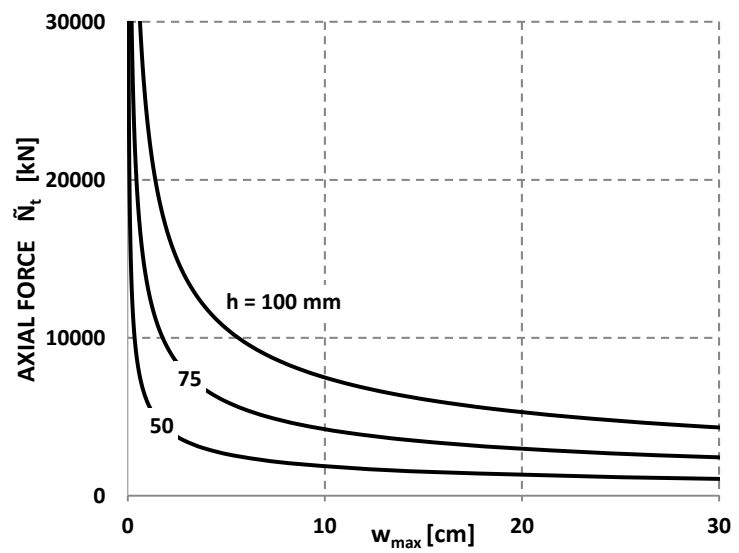

Figure 7: Axial forces, Ñt, for UTRCP with a joint/crack (left) and without a joint/crack (right)

The relationship between concrete thickness and the maximum safe allowable temperature increase that the pavement can experience before a blow-up, is indicated in Figure 8. It is clear that the temperature increase required to cause a blow-up in an ultra-thin concrete pavement is considerably lower than for conventional CRCP pavements.

The temperature increase required for a blow-up in ultra-thin concrete pavements with a thickness of 50 $\mathrm{mm}$, can be less than $15^{\circ} \mathrm{C}$ as indicated in Figure 4. It is therefore of importance for the designer of an ultra-thin concrete pavement to take into consideration the minimum temperature increase required to cause a blowup and limit the construction temperature accordingly.

The deterioration of cracks in an ultra-thin concrete pavement may further increase the risk of a blow-up at even lower temperatures than that of a newly constructed (without a joint/crack) pavement. Transverse cracks in an ultra-thin concrete pavement can occur and reduce the bending stiffness of the concrete, depending on the depth of the crack.

For rectangular shapes, an $8 \mathrm{~mm}$ deep crack in a 50 $\mathrm{mm}$ thick pavement will incur a $40 \%$ reduction in bending stiffness in the concrete used, as an example. This implies only about $60 \%$ remaining bending stiffness if a crack nearly one sixth the depth is present within the pavement.

This will cause the temperature increase for a blowup to occur, to lie between the above-mentioned values with and without a joint. The effect of $40 \%$ bending stiffness due to a possible crack in the pavement is shown in Figure 8.

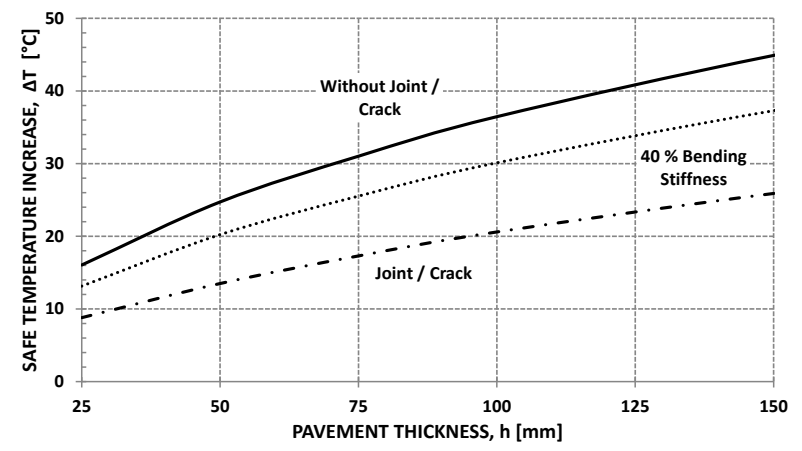

Figure 8: Pavement thickness influence on safe temperature increase for different bending stiffness situations

\section{Safe Temperature Ranges}

In rail track design, more specifically the design of Continuously Welded Rails (CWR), the rails need to be fixed and destressed within certain temperature ranges. This will ensure that tension and compression forces within the rail are limited to reduce the risk of buckling failures.

With ultra-thin concrete pavements being prone to temperature related failures, the need to identify possible safe temperature ranges for casting of the concrete was recognized. With bridge construction, the maximum daily air temperature of the day before, and the minimum night time air temperature for the morning of the casting a concrete expansion joint is used to determine the installation temperature [23]. A similar approach to the construction temperatures of UTRCP is proposed where the average of the two values is taken as the installation temperature.

The lower construction temperature limit is currently dependent on axial thermal expansion forces within the pavement while the upper temperature limit is dependent on concrete regulations with regard to maximum casting 
temperatures. It must be noted that daily thermal expansion of the pavement can cause large movements exceeding that caused by shrinkage [24].

Temperature rise during construction in thin, exposed members are usually small, regardless of the mixture or type of cement used. The temperature of the concrete will be slightly above the ambient air temperatures and the stable installation temperature of the concrete will approximate the geographical annual average air temperature [25]

\subsection{Upper Temperature Limit}

The main factor influencing the upper construction temperature limit is strain within the concrete. If the concrete pavement exceeds the allowed strain in thermal contraction, the pavement may not be able to recover the strain and therefore create a permanent defect.

Most of the shrinkage occurs in the initial drying of the concrete, where a large part cannot be recovered [26]. The CSIR guideline for ultra-thin concrete pavement construction allows for construction joints between two adjacent sections of pavement that are cast later than 48 hours apart [27]. However, this would reduce the amount of recoverable shrinkage since the length of the earlier cast pavement is reduced due to the time it has been allowed to shrink. Since most of the shrinkage will occur at the free end of the pavement, this reduces the recoverable shrinkage capacity of the pavement [26].

Accordingly, an upper construction limit of $35^{\circ} \mathrm{C}$ can be seen as the maximum permissible temperature for local conditions as per the South African National Standard 878:2012 [28]. Hot weather concreting at temperatures above $35^{\circ} \mathrm{C}$ is in any event usually not permitted as water evaporation and early age cracking becomes a problem [29].

\subsection{Lower temperature limit}

To determine the lower temperature limit, the expected maximum temperature of the pavement needs to be known. While asphalt pavement maximum temperatures are well documented in South Africa, limited information on concrete pavement temperatures are known. Ambient temperatures are generally slightly lower than that of the pavement surface due to concrete's thermal absorptivity from the sun's radiation [6]. A relationship between ambient temperature and surface temperature of concrete pavements has not been established, and due to the thickness of ultra-thin concrete pavements, ambient temperatures were assumed for concrete temperatures in this study.

If the maximum temperature that an ultra-thin concrete pavement can experience on a specific site is assumed to be $40{ }^{\circ} \mathrm{C}$, as indicated by SCT 22 [30], the lower limit (LL) is determined as follows:
As shown earlier, for a $50 \mathrm{~mm}$ thick ultra-thin concrete pavement with a transverse crack, approximately $13 \mathrm{~mm}$ deep, (40\% reduced stiffness) the value of $\triangle \mathrm{TL}$ is equal to $20.5{ }^{\circ} \mathrm{C}$ for UTRCP. The lower construction temperature limit is equal to $19.5^{\circ} \mathrm{C}$. The sensitivity of the pavement to temperature and the condition thereof is clear from this analysis.

\section{Discussion}

Following the analysis above, a safe construction temperature graph for a $50 \mathrm{~mm}$ thick ultra-thin concrete pavement can be produced as shown in Figure 9 for an illustrative site. Note that the highest expected temperature of $40^{\circ} \mathrm{C}$ represents the highest expected concrete temperature of the pavement during the hot summer months at this illustrative site.

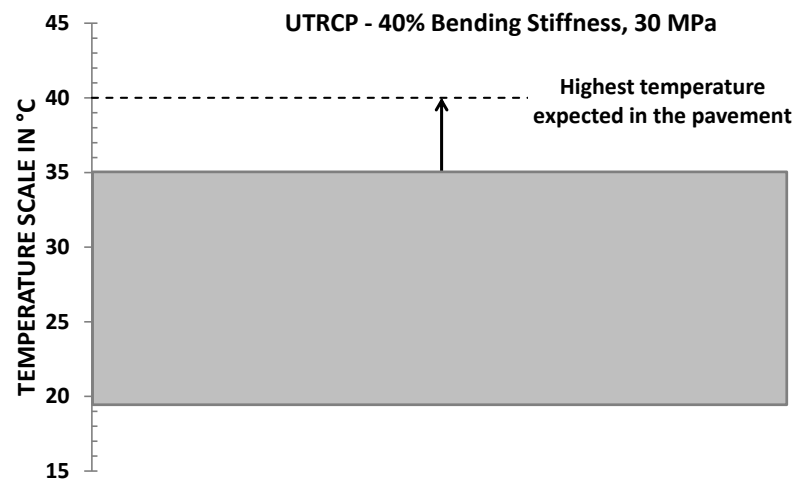

Figure 9: Safe construction temperature range graph indicating the range of temperatures at which ultra-thin concrete pavements should be constructed to minimize the risk of a blow-up failure for the illustrative site considered

The specifications supplied by the Standard Specifications for Road and Bridge Works for State Road Authorities (COLTO) as well as South African National Standard 878:2012, state that concrete may be placed at temperatures as low as $5{ }^{\circ} \mathrm{C}$ [31], [28].This was adopted for UTCRP [27]. Although such low temperatures may be expected on site and even lower, to construct the ultra-thin concrete pavement at such temperatures may lead to significant blow-ups occurring within the pavement.

The above analysis was repeated for different possible site temperatures and a range of possible pavement construction thicknesses to establish a guide for minimum construction temperatures as shown in Table 2. The use of a reduced bending stiffness of $40 \%$ was applied to represent possible defects that may occur within the pavement and considered appropriately conservative for design.

$$
L L=\operatorname{Max} T-\Delta T_{L}
$$


Table 2 : Minimum construction temperatures for UTRCP associated with the maximum expected site temperature and pavement thickness

\begin{tabular}{|c|c|c|c|c|c|}
\hline \multirow{2}{*}{$\begin{array}{c}\text { Pavement } \\
\text { thickness }\end{array}$} & \multicolumn{5}{|c|}{ Maximum expected site temperature } \\
\cline { 2 - 6 }$[\mathrm{mm}]$ & 24 & 28 & 32 & 36 & 40 \\
\hline 50 & 5 & 8 & 12 & 16 & 20 \\
\hline 60 & 5 & 5 & 9 & 13 & 17 \\
\hline 70 & 5 & 5 & 7 & 11 & 15 \\
\hline 80 & 5 & 5 & 5 & 9 & 13 \\
\hline 90 & 5 & 5 & 5 & 7 & 11 \\
\hline 100 & 5 & 5 & 5 & 5 & 9 \\
\hline
\end{tabular}

\section{Conclusion and Recommendations}

With an increase in temperature, an axial force is induced within a concrete pavement. The axial force may then lead to a blow-up in the pavement where there is a vertical displacement of the pavement over a certain length. The magnitude of the temperature increase, consequent induced axial force and magnitude of displacement was calculated for ultra-thin concrete pavements.

An interim guideline was developed that will allow designers in future to specify the minimum safe construction temperature for UTRCP pavements for specific site temperatures. The safe temperature range can also be referred to as a neutral temperature range where the pavement is not in danger of experiencing excessive temperature induced axial forces or excessive strain with a temperature decrease. The lowest allowable construction temperature as stated by COLTO [31] and SANS $878: 2012$ is $5^{\circ} \mathrm{C}$, but to construct ultra-thin pavements at this temperature could be detrimental and may lead to blow-up failures.

The temperatures at which blow-ups occur need to be confirmed by laboratory and/or full scale testing to substantiate the analysis done. The validation of the calculated low construction temperatures is the focus of a study that is currently being undertaken by the authors on a number of recent blow-up failure sites.

\section{References}

[1] L. Kannemeyer, B. D. Perrie, P. J. Strauss, and L. du Plessis, "Ultra Thin Continuously Reinforced Concrete Pavement Research in South Africa," in International Conference on Concrete Roads, 2007, pp. 1-27.

[2] M. W. K. E. Mukandila, T. I. Milne, and E. Horak, "Constructibility aspects of Ultra thin continuously reinforced concrete pavement," in 28th Southern African Transport Conference, 2009, no. July, pp. 234-244.

[3] H. J. Brink, "Ultra Thin Reinforced Concrete Pavement: Practical Applications," in 31st Southern African Transport Convention, 2012, no. July, pp. 168-175.

[4] A. D. Kerr, "Blowup of a concrete pavement adjoining a rigid structure," Int. J. Non. Linear. Mech., vol. 29, no. 3, pp. 387-396, May 1994.

[5] A. D. Kerr, P. J. Shade, and F. Park, "Analysis of Concrete Pavement Blowups," Acta Mech., vol. 52, pp. 201-224, 1984.

[6] J. M. Vandenbossche, "The measured response of ultra-thin and thin whitetopping to environmental loads," in 7th International Conference on Concrete Pavements. The Use of Concrete in Developing Long-Lasting Pavement Solutions for the 21st Century, 2001, pp. 807-823.

[7] US Army Corps of Engineers, "Technical Instructions Railroad Design and Rehabilitation," vol. 1125, no. March, 2000.

[8] K. B. Woods, H. S. Sweet, and T. E. Shelburne, "Pavement blowups correlated with source of coarse aggregate," Highw. Res. Board, vol. 25, no. Proceedings, 1946.

[9] F. N. Hveem, "Types and causes of failure in highway pavements," Highw. Res. Board Bull., no. 187, 1958.

[10] M. J. Hensley, "The study of pavement blowups," Little Rock, Arkansas, 1966.

[11] D. Bowers, A study of the failures occurring in the concrete pavement of the Connecticut Turnpike and roads of similar design. Wethersfield, Connecticut: Connecticut State Highway Deptartment, 1966.

[12] M. Graham and W. Chamberlin, "Summary of 1966 rigid pavement blowup survey," New York, 1967.

[13] J. P. Stott and K. M. Brook, "Report on a visit to USA to study blow-ups in concrete roads," British Ministry of Transport, 1968.

[14] D. E. Gordinier and W. P. Chamberlin, "Pressure relief joints for rigid pavements," Albany, New York, 1968.

[15] M. P. Burke, "The world's most expensive pavement expansion joints," in Ohio Highway Engineering Conference Proceedings, 1972.

[16] P. T. Foxworthy, "Statewide survey of blowups in resurfaced concrete pavements," Purdue University, West Lafayette, Indiana, 1973.

[17] D. Gress, "Blow-ups on Resurfaced Concrete Pavements," West Lafayette, Indiana, 1974.

[18] A. D. Kerr, "Assessment of Concrete Pavement Blowups," J. Transp. Eng., vol. 123, no. 2, pp. 123-131, 1997.

[19] Uni En, "BS EN 1992-1-1:2004 - Eurocode 2: Design of concrete structures - Part 1-1: General rules and rules for buildings," Eurocode 2, vol. 1, no. 2004, 2004.

[20] South African Bureau of Standards, The Structural Use of Concrete - Part 1: Design SABS 10100-1. 2000.

[21] British Standard, Structural use of concrete - Part 1. Code of practice for design and construction. 1997.

[22] ACI Committee, Report on High-Strength Concrete (ACI 363R-10). 2010.

[23] C. W. Roeder, "Thermal Movement Design Procedure for Steel and Concrete Bridges," Seattle, Washington, 2002. 
[24] B. Mosley, J. Bungey, and R. Hulse, Reinforced Concrete Design: to Eurocode 2, Seventh. London: Palgrave MacMillan, 2012.

[25] S. B. Tatro, J. C. Allen, A. A. Bombich, B. D. Fehl, and G. R. Mass, "Report on Thermal and Volume Change Effects on Cracking of Mass Concrete ACI 207.2R-07," 2007.

[26] M. Alexander and H. Beushausen, "Deformation and volume change of hardened concrete," in Fulton's Concrete Technology, Ninth., G. Owens, Ed. Midrand: Cement and Concrete Institute, 2009, pp. 111-154.

[27] CSIR, "Guidelines for the construction of a $50 \mathrm{~mm}$ thick Ultra Thin Reinforced Concrete Pavement (50mm UTRCP)," Council for Scientific and Industrial Research, 2008.

[28] South African Bureau of Standards, Ready-mixed concrete SANS 878:2012. 2012.

[29] R. Rasmussen, R. Rogers, and T. Ferragut, "Continuously Reinforced Concrete Pavement: Design and Construction Guidelines," Washington, DC, 2009.

[30] Cement and Concrete Institute, SCT 22 Concrete Road Design and Construction. Cement and Concrete Institute, 2011.

[31] Committee of Land Transport Officials, Standard Specifications for Road and Bridge Works for State Road Authorities. 1998. 